\title{
Sex-related differences in access to care among patients with premature acute coronary syndrome
}

\author{
Roxanne Pelletier PhD, Karin H. Humphries DSc, Avi Shimony MD, Simon L. Bacon PhD, Kim L. Lavoie PhD, \\ Doreen Rabi MD MS, Igor Karp MD PhD, Meytal Avgil Tsadok PhD, Louise Pilote MD PhD; for the GENESIS- \\ PRAXY Investigators*
}

\begin{abstract}
Background: Access to care may be implicated in disparities between men and women in death after acute coronary syndrome, especially among younger adults. We aimed to assess sex-related differences in access to care among patients with premature acute coronary syndrome and to identify clinical and gender-related determinants of access to care.
\end{abstract}

Methods: We studied 1123 patients (18-55 yr) admitted to hospital for acute coronary syndrome and enrolled in the GENESIS-PRAXY cohort study. Outcome measures were door-toelectrocardiography, door-to-needle and door-toballoon times, as well as proportions of patients undergoing cardiac catheterization, reperfusion or nonprimary percutaneous coronary intervention. We performed univariable and multivariable logistic regression analyses to identify clinical and gender-related determinants of timely procedures and use of invasive procedures.

Results: Women were less likely than men to receive care within benchmark times for electrocardiography ( $\leq 10 \mathrm{~min}: 29 \%$ v. $38 \%, p=0.02$ ) or fibrinolysis ( $\leq 30 \mathrm{~min}$ : $32 \%$ v. $57 \%, p=0.01$ ). Women with ST-segment elevation myocardial infarction (MI) were less likely than men to undergo reperfusion therapy (primary percutaneous coronary intervention or fibrinolysis) $(83 \%$ v. $91 \%, p=0.01)$, and women with non-STsegment elevation $\mathrm{Ml}$ or unstable angina were less likely to undergo nonprimary percutaneous coronary intervention ( $48 \%$ v. $66 \%, p<0.001)$. Clinical determinants of poorer access to care included anxiety, increased number of risk factors and absence of chest pain. Gender-related determinants included feminine traits of personality and responsibility for housework.

Interpretation: Among younger adults with acute coronary syndrome, women and men had different access to care. Moreover, fewer than half of men and women with ST-segment elevation $\mathrm{MI}$ received timely primary coronary intervention. Our results also highlight that men and women with no chest pain and those with anxiety, several traditional risk factors and feminine personality traits were at particularly increased risk of poorer access to care.
Competing interests: For activities outside the scope of the study reported here, Simon Bacon has received personal fees from Kataka Medical Communication and Kim Lavoie has received consultancy and/or presentation fees from Takeda, AbbVie,

Boehringer Ingelheim and Merck. No other competing interests declared.

This article has been peer reviewed.

*The complete list of GENESIS-PRAXY Investigators appears at the end of the article. The participating centres are listed in Appendix 1 (available at www.cmaj.ca /lookup/suppl/doi:10.1503 /cmaj.131450/-/DC1).

Correspondence to: Louise Pilote, louise.pilote@mcgill.ca

CMAJ 2014. DOI:10.1503 /cmaj.131450
$\mathrm{D}$ espite improvements in the management of acute coronary syndrome over the past few decades, differences in mortality between men and women persist, especially among younger adults. ${ }^{1}$ The reasons for poorer outcomes among women are thought to be multifactorial and may include higher baseline prevalence of risk factors for cardiovascular disease ${ }^{2-4}$ and poorer access to care..$^{2-6}$ However, in the cited studies, patients were relatively old, and only one study ${ }^{4}$ considered clinical factors as potential confounders in the relationship. Moreover, determinants of access to care in men and women with premature acute coronary syndrome remain unknown.

The effect of gender-related factors on access to care has not been investigated. Unlike sex, which is a biological characteristic, gender has a wider scope, incorporating the effects of social norms and expectations for men and women. Gender-related variables include gender identity, social roles, socioeconomic status and interpersonal relationships. There has been a considerable reduction in the gender gap in North America in the past decades. ${ }^{7}$ As a result, more women are gaining access to education and employment, and sharing of household and workplace responsibilities is becoming more common. Therefore, assessing sex alone cannot adequately account for differences in access to care among young adults with premature acute coronary syndrome. To better understand differences in access to care between men and women, a detailed examination of both sex- and gender-related factors is required.

Our primary objective in this study was to assess sex-related differences in access to care 
among adults with premature acute coronary syndrome. Our secondary objective was to identify clinical and gender-related determinants of access to care among men and women.

\section{Methods}

\section{Study design}

The GENESIS-PRAXY (GENdEr and Sex determInantS of cardiovascular disease: from bench to beyond - PRemature Acute Coronary SYndrome) study is a multicentre, prospective study involving follow-up of patients with premature acute coronary syndrome. Between January 2009 and April 2013, 24 centres across Canada, 1 in the United States and 1 in Switzerland recruited patients. The study's design and methods have been described previously. ${ }^{8}$ In reporting this study, we have followed the STROBE guidelines for observational studies. ${ }^{9}$

\section{Study population and data sources}

Eligible patients were adults aged 18 to 55 years, fluent in English or French, able to provide informed consent and admitted to hospital with a diagnosis of acute coronary syndrome. A research nurse approached each eligible patient in the coronary care unit within 24 hours after admission. Upon recruitment, each participant was asked to complete a self-administered questionnaire, and anthropometric measurements were obtained. A research nurse reviewed each patient's medical chart to collect medical history, current characteristics related to acute coronary syndrome and procedure data.

\section{Demographic and clinical characteristics}

We determined participants' demographic and clinical characteristics from self-reported and chart data. Previous cardiovascular disease events were myocardial infarction (MI), stroke, peripheral arterial disease, coronary artery bypass graft and percutaneous intervention. We calculated body mass index from height and weight and defined obesity as body mass index of 30 or more. We assessed symptoms of depression and anxiety that were present before the onset of acute coronary syndrome using the Hospital Anxiety and Depression Scale. ${ }^{10}$

\section{Gender-related factors}

We assessed gender-related variables associated with gender identity, social roles, socioeconomic status and interpersonal relationships. We assessed responsibility for housework by asking, "Are you the primary person responsible for doing housework?" We evaluated masculinity and femininity using the Bem Sex Role Inventory, ${ }^{11}$ a self-report questionnaire that character- izes a respondent's personality as masculine, feminine, androgynous or undifferentiated. The questionnaire is based on gender stereotypes and therefore measures how well a person fits into traditional sex roles. We assessed perceived social standing with the MacArthur Perceived Social Standing Scale ${ }^{12}$ and measured perceived social support with the ENRICHD (Enhancing Recovery in Coronary Heart Disease Patients) Social Support Instrument. ${ }^{13}$

\section{Outcome measures}

For all patients, we calculated door-to-electrocardiography (ECG) time as the interval between arrival at the emergency department and the first ECG examination. For patients with ST-segment elevation MI, we calculated door-to-needle time as the interval between arrival at the emergency department and the start of administration of fibrinolytics. For patients with ST-segment elevation MI undergoing primary percutaneous intervention, we calculated door-to-balloon time as the interval between arrival at the emergency department and first balloon inflation. For patients with non-ST-segment elevation MI, we determined use of cardiac catheterization from chart review. Reperfusion procedures included primary percutaneous intervention and fibrinolytic therapy in patients with ST-segment elevation MI. We determined door-to-ECG, door-to-needle and door-toballoon times, as well as the utilization of cardiac catheterization, reperfusion therapy and nonprimary percutaneous interventions, using a detailed data extraction form based on chart review.

\section{Statistical analyses}

We used descriptive statistics to compare (between men and women) baseline characteristics; door-toECG, door-to-needle and door-to-balloon times; and utilization of invasive procedures. We also calculated the proportion of patients who underwent ECG, received fibrinolytic therapy or received primary percutaneous intervention within the benchmark times set by the American College of Cardiology and the American Heart Association ${ }^{14}$ (10 $\mathrm{min}, 30 \mathrm{~min}$ and $90 \mathrm{~min}$, respectively). We compared continuous variables using 2-sample $t$ tests or Wilcoxon tests, as appropriate, and compared dichotomous variables with $\chi^{2}$ tests.

To identify the clinical and gender-related determinants of timeliness of procedures and utilization of invasive procedures, we performed univariable and multivariable logistic regressions. The multivariable models incorporated age, ethnicity, depression, anxiety, previous cardiovascular events, absence of chest pain, number of cardiovascular risk factors, Bem femininity and masculinity scores, employment status, perceived 
social standing, housework responsibility status, education level and low social support. For each outcome for which a clinical and/or genderrelated determinant was identified, the interaction effect between sex and the predictor was tested by adding sex, as well as an interaction term between sex and the determinant, to its respective model.

We included depression and anxiety symptoms as continuous variables in the regression models and as binary variables in the descriptive analysis. Clinically significant depression and anxiety were defined as a score of 8 or above on the depression and anxiety subscales, respectively, of the Hospital Anxiety and Depression Scale. ${ }^{15}$

All statistical analyses were performed using SAS version 9.2 (Cary, North Carolina). Statistical tests were 2-sided; differences with $p \leq 0.05$ were considered statistically significant.

Table 1: Baseline characteristics of patients included in a study of access to care for premature acute coronary syndrome

\begin{tabular}{|c|c|c|c|}
\hline \multirow[b]{2}{*}{ Characteristic } & \multicolumn{2}{|c|}{ Sex; no. (\%) of patients* } & \multirow[b]{2}{*}{$p$ value } \\
\hline & $\begin{array}{l}\text { Women } \\
n=362\end{array}$ & $\begin{array}{c}\text { Men } \\
n=761\end{array}$ & \\
\hline \multicolumn{4}{|l|}{ Sociodemographic } \\
\hline Age, yr, median (IQR) & 50 (7) & $49(8)$ & 0.8 \\
\hline White ethnicity & $322(89)$ & $660(87)$ & 0.3 \\
\hline Married & $170(47)$ & $388(51)$ & 0.2 \\
\hline Low household annual income $(<\$ 50000) \dagger$ & $146(48)$ & $186(29)$ & $<0.001$ \\
\hline \multicolumn{4}{|l|}{ Clinical } \\
\hline Significant depression (HADS subscale score $\geq 8$ ) & $102(28)$ & $158(21)$ & 0.01 \\
\hline Significant anxiety (HADS subscale score $\geq 8$ ) & $195(54)$ & $279(37)$ & $<0.001$ \\
\hline Postmenopausal & $181(50)$ & NA & \\
\hline Previous cardiovascular events & $105(29)$ & $141(19)$ & $<0.001$ \\
\hline Family history of cardiovascular disease & $100(28)$ & $150(20)$ & 0.003 \\
\hline Obesity & $155(43)$ & $299(39)$ & 0.3 \\
\hline Diabetes mellitus & $85(23)$ & $107(14)$ & $<0.001$ \\
\hline Dyslipidemia & $196(54)$ & $427(56)$ & 0.5 \\
\hline Hypertension & $198(55)$ & $346(45)$ & 0.004 \\
\hline Smoking & $156(43)$ & $293(39)$ & 0.1 \\
\hline \multicolumn{4}{|l|}{ Characteristics at presentation } \\
\hline Absence of chest pain at ACS presentation & 70 (19) & $116(15)$ & 0.1 \\
\hline $\begin{array}{l}\text { Delay between onset of pain and arrival } \\
\text { in emergency department, } \mathrm{h} \text { (median, IQR) }\end{array}$ & 4 (9) & $3.5(8)$ & 0.3 \\
\hline STEMI & $174(48)$ & $478(63)$ & $<0.001$ \\
\hline NSTEMI & $139(38)$ & $225(30)$ & 0.003 \\
\hline Unstable angina & $40(11)$ & $42(6)$ & $<0.001$ \\
\hline \multicolumn{4}{|l|}{ Gender-related characteristics } \\
\hline Femininity, Bem score, mean \pm SD & $6.0 \pm 0.8$ & $5.5 \pm 0.9$ & $<0.001$ \\
\hline Masculinity, Bem score, mean \pm SD & $4.8 \pm 0.9$ & $5.3 \pm 0.9$ & $<0.001$ \\
\hline Currently employed & $242(67)$ & $640(84)$ & $<0.001$ \\
\hline PSSS score, mean \pm SD & $5.6 \pm 2.0$ & $6.1 \pm 2.0$ & $<0.001$ \\
\hline Housework responsibility & $279(77)$ & $211(28)$ & $<0.001$ \\
\hline Postsecondary education & $197(54)$ & $490(64)$ & 0.001 \\
\hline Low perceived social support (based on ESSI score) & $99(27)$ & $184(24)$ & 0.3 \\
\hline \multicolumn{4}{|c|}{ 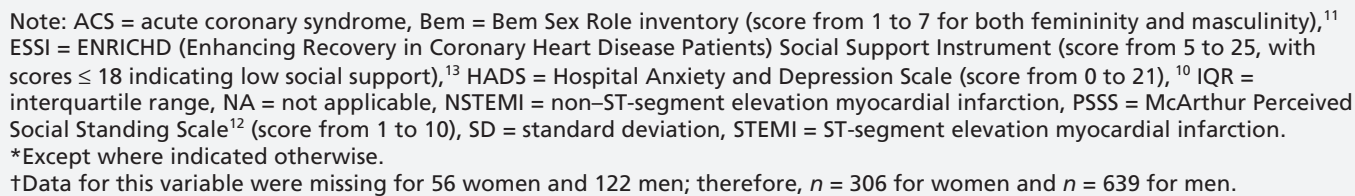 } \\
\hline
\end{tabular}




\section{Results}

\section{Patient characteristics}

The study population consisted of 362 women (32\%) and 761 men $(68 \%)$ with baseline and self-reported questionnaire data (Table 1) (see Appendix 2, available at www.cmaj.ca/lookup /suppl/doi:10.1503/cmaj.131450/-/DC1, for patient flow diagram). The median age was 50 (interquartile range [IQR] 7) years for women and 49 (IQR 8) years for men. Relative to men, women had significantly lower income levels, higher prevalences of diabetes mellitus, hypertension, family history of cardiovascular disease and previous cardiovascular disease events, and significantly more depression and anxiety before the onset of acute coronary syndrome. Women were less likely to have a diagnosis of ST-segment elevation MI and more likely to have a diagnosis of non-ST-segment elevation MI or unstable angina. The median time between the onset of chest pain and presentation to the emergency department was 4 hours for women and 3.5 hours for men.

Regarding gender-related characteristics, women had higher femininity scores and lower masculinity scores (Table 1). In addition, women were less likely to be employed, had a lower education level, were more often responsible for housework and reported lower levels of perceived social standing than men.

\section{Sex differences in time to procedure}

Median times to procedures for men and women, respectively, were 21 and 15 minutes for ECG, 36 and 28 minutes for fibrinolytic therapy, and 106 and 93 minutes for primary percutaneous interven-

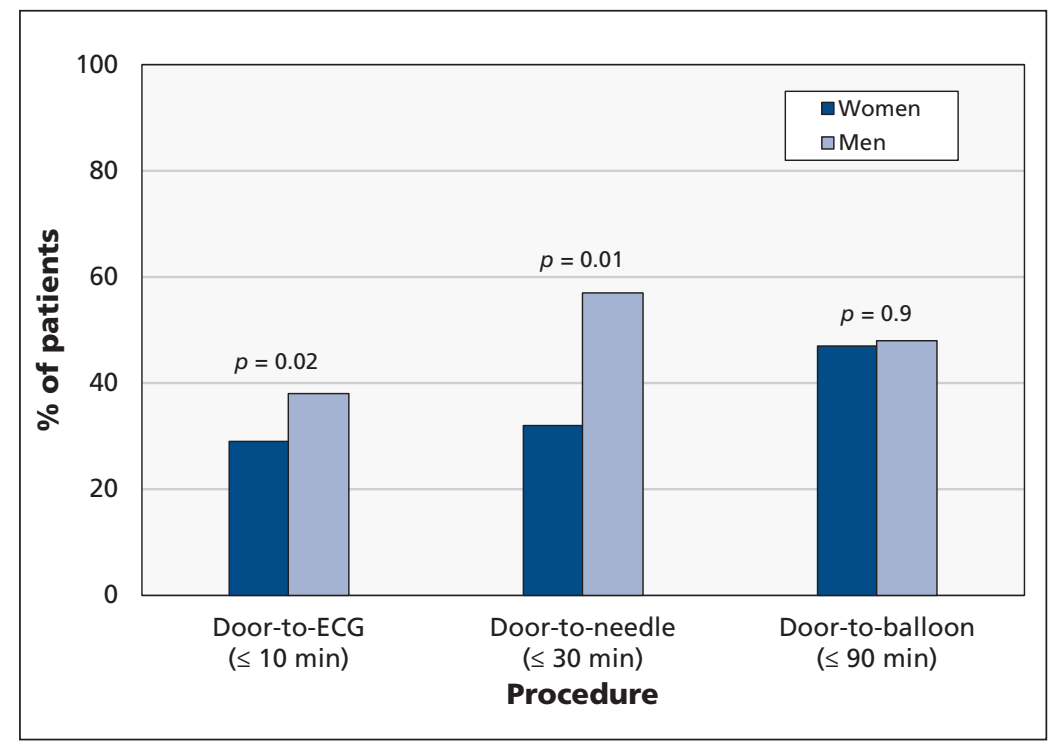

Figure 1: Proportions of women and men for which procedures were performed within benchmark times, as defined by the American Heart Association and the American College of Cardiology. ${ }^{14}$ tion (Table 2). Women were less likely than men to receive timely ECG $(\leq 10 \mathrm{~min} ; 29 \%$ v. $38 \%, p=$ $0.02)$ and fibrinolytic therapy $(\leq 30 \mathrm{~min} ; 32 \% \mathrm{v}$. $59 \%, p=0.01$ ), according to established benchmarks $^{14}$ (Figure 1). There was no difference in the proportions of men and women receiving timely primary percutaneous intervention.

\section{Sex differences in invasive procedures}

Among patients with ST-segment elevation MI, women were less likely than men to receive reperfusion therapy, and among patients with non-ST-segment elevation MI or unstable angina, women were also less likely to receive nonprimary percutaneous intervention (Table 2). Among patients with non-ST-segment elevation MI, the proportions of men and women who underwent cardiac catheterization were similar.

\section{Determinants of procedure delays}

Multivariable logistic regression revealed that the presence of anxiety, a higher number of risk factors for cardiovascular disease and the absence of chest pain at presentation were independently associated with lower odds of undergoing a timely procedure. Adjusted analyses also revealed some statistically significant associations suggesting that patients with higher Bem feminity scores had lower odds of undergoing timely procedures, whereas patients with high Bem masculinity scores had higher odds of undergoing timely procedures (Table 3).

Multivariable analyses incorporating the interaction between sex and various determinants of procedure delays revealed only one interaction effect, for anxiety in relation to timely ECG. Specifically, women with anxiety had a lower probability of undergoing ECG within the recommended 10 minutes than women without anxiety $(33 / 140$ [24\%] v. $39 / 110$ [35\%], $p=0.04)$, an effect not observed for men with and without anxiety $(70 / 191$ [37\%] v. 124/325 [38\%], $p=$ $0.8)$. The absence of an interaction between sex and other determinants of procedure delays suggests that the number of cardiovascular risk factors, the absence of chest pain at presentation, low social support and Bem masculinity and femininity scores were associated with procedure delays to a similar extent in men and women.

\section{Determinants of utilization of invasive procedures}

Multivariable logistic regression models revealed that gender-related but not clinical determinants were independently associated with the utilization of various procedures. Specifically, patients who reported being responsible for housework had lower odds of undergoing catheterization and receiving nonprimary percutaneous interven- 
tion than patients who reported not being responsible for housework. Patients with higher Bem femininity scores also had lower odds of undergoing nonprimary percutaneous interventions than patients with lower feminine traits of personality (Table 4).
There was no interaction effect between sexand gender-related determinants of procedure utilization, which suggests that housework responsibility and increased feminine personality traits decreased the odds of procedure utilization to a similar extent among men and women.

Table 2: Timeliness of procedures and use of invasive procedures among men and women with acute coronary syndrome

\begin{tabular}{|c|c|c|c|}
\hline Variable & Women & Men & $p$ value \\
\hline \multicolumn{4}{|l|}{ Timeliness of procedures } \\
\hline Door-to-ECG time, min, median (IQR) & $21(49)$ & $15 \quad(32)$ & $<0.001$ \\
\hline Door-to-needle time, min, median (IQR)* & $36(62)$ & $28(30)$ & 0.02 \\
\hline Door-to-balloon time, min, median (IQR) $\dagger$ & $106(77)$ & $93(102)$ & 0.7 \\
\hline \multicolumn{4}{|l|}{ Invasive procedures, no. (\%) of patients } \\
\hline Cardiac catheterization, among those with NSTEMI & $319 / 362(88)$ & $670 / 761 \quad(88)$ & 0.9 \\
\hline Reperfusion, among those with STEMI & $145 / 174(83)$ & $433 / 478$ (91) & 0.01 \\
\hline Nonprimary PCI, among those with NSTEMI or UA & $87 / 181(48)$ & $181 / 273(66)$ & $<0.001$ \\
\hline \multicolumn{4}{|c|}{$\begin{array}{l}\text { Note: } E C G \text { = electrocardiography, IQR = interquartile range, NSTEMI = non-ST-segment elevation myocardial infarction, } \mathrm{PCI}= \\
\text { percutaneous coronary intervention, STEMI = ST-segment elevation myocardial infarction, UA = unstable angina. } \\
\text { *Data for patients with STEMI who underwent fibrinolytic therapy. } \\
\text { †Data for patients with STEMI who underwent primary PCI. }\end{array}$} \\
\hline
\end{tabular}

Table 3: Multivariable logistic regression for determinants of timely use of procedures*

\begin{tabular}{|c|c|c|c|}
\hline \multirow[b]{2}{*}{ Factor } & \multicolumn{3}{|c|}{ Cutoff for timeliness; OR $(95 \% \mathrm{Cl})$} \\
\hline & $\begin{array}{l}\text { Door-to-ECG } \\
\leq 10 \mathrm{~min}\end{array}$ & $\begin{array}{l}\text { Door-to-needle } \\
\quad \leq 30 \mathrm{~min}\end{array}$ & $\begin{array}{l}\text { Door-to-balloon } \\
\leq 90 \mathrm{~min}\end{array}$ \\
\hline \multicolumn{4}{|l|}{ Clinical } \\
\hline $\begin{array}{l}\text { Anxiety, per 1-point increment on HADS } \\
\text { subscale }\end{array}$ & $0.95(0.90-0.99)$ & $1.01(0.88-1.15)$ & $1.03(0.96-1.11)$ \\
\hline $\begin{array}{l}\text { Depression, per 1-point increment } \\
\text { on HADS subscale }\end{array}$ & $1.05(0.99-1.11)$ & $1.10(0.95-1.24)$ & $0.97(0.89-1.06)$ \\
\hline Absence of chest pain & $0.77(0.49-1.20)$ & $0.98(0.27-3.49)$ & $0.41(0.18-0.92)$ \\
\hline Previous event & $0.55(0.36-1.84)$ & $0.53(0.13-2.15)$ & $0.74(0.39-1.44)$ \\
\hline $\begin{array}{l}\text { CVD risk factors, per each added risk } \\
\text { factor }\end{array}$ & $1.01(0.89-1.15)$ & $0.70(0.48-0.99)$ & $0.83(0.68-1.01)$ \\
\hline \multicolumn{4}{|l|}{ Gender-related } \\
\hline Postsecondary education & $1.27(0.91-1.77)$ & $2.13(0.90-4.03)$ & $1.49(0.92-2.43)$ \\
\hline Employed & $1.16(0.74-1.79)$ & $1.51(0.43-4.25)$ & $0.95(0.50-1.81)$ \\
\hline $\begin{array}{l}\text { Perceived social standing within } \\
\text { community (based on PSSS score) }\end{array}$ & $1.00(0.89-1.06)$ & $1.03(0.80-1.32)$ & $0.96(0.85-1.09)$ \\
\hline Responsibility for housework & $0.80(0.58-1.12)$ & $0.60(0.25-1.49)$ & $1.35(0.83-2.19)$ \\
\hline Low social support (based on ESSI scale) & $1.26(0.87-1.82)$ & $2.78(1.01-5.55)$ & $1.00(0.56-1.80)$ \\
\hline $\begin{array}{l}\text { Femininity, per 1-point increment } \\
\text { on Bem scale }\end{array}$ & $1.03(0.85-1.23)$ & $0.75(0.47-1.21)$ & $0.69(0.53-0.89)$ \\
\hline $\begin{array}{l}\text { Masculinity, per 1-point increment } \\
\text { on Bem scale }\end{array}$ & $1.07(0.90-1.28)$ & $1.62(1.00-2.66)$ & $1.13(0.86-1.47)$ \\
\hline \multicolumn{4}{|c|}{$\begin{array}{l}\text { Note: Bem }=\text { Bem Sex Role Inventory, }{ }^{11} \mathrm{Cl}=\text { confidence interval, } \mathrm{CVD}=\text { cardiovascular disease, } \mathrm{ECG}=\text { electrocardiography, ESSI = } \\
\text { ENRICHD (Enhancing Recovery in Coronary Heart Disease Patients) Social Support Instrument, }{ }^{13} \mathrm{HADS}=\text { Hospital Anxiety and } \\
\text { Depression Scale, }{ }^{10} \mathrm{OR}=\text { odds ratio, PSSS }=\text { McArthur Perceived Social Standing Scale. }{ }^{12} \\
{ }^{*} \text { The results for each row were adjusted for all other factors in the table, as well as for age and ethnicity; sex was not included } \\
\text { in the model. }\end{array}$} \\
\hline
\end{tabular}




\section{Interpretation}

Within our cohort of younger adults with acute coronary syndrome, women and men had differing access to care. Moreover, fewer than half of all women and men received timely ECG, fibrinolysis and primary percutaneous coronary intervention. Our results also highlight that young men and women with no chest pain and those with anxiety, several traditional risk factors and feminine personality traits were at particularly increased risk of poor access to care.

Our results indicating that lower proportions of women than men received timely ECG and fibrinolysis present a clinical challenge in providing appropriate care. Indeed, failure to meet benchmark door-to-ECG and door-to-needle times has been associated with an increased risk of death and recurrent events among patients with ST-segment elevation MI. ${ }^{16,17}$ Notably, within our entire sample, the benchmarks for timely procedures (including primary percutaneous intervention) were achieved for low proportions of both men and women, with fewer than half of all patients undergoing these procedures within the recommended time frames. As such, there is room for improvement in the identification and treatment of acute coronary syndrome among younger adults, especially young women.

We also observed that, relative to men, women with ST-segment elevation MI were less likely to undergo reperfusion therapy. The longer delay between the onset of chest pain and presentation among older women than among older men in previous studies ${ }^{18}$ may explain the lower odds of reperfusion observed in older women, but this phenomenon does not appear to have been in effect in our cohort. Indeed, the delay between the onset of chest pain and presentation was similarly long for both women and men (4 v. $3.5 \mathrm{~h}$ ).

The determinants of procedure delays and utilization of invasive procedures that we identified may help in explaining sex-related differences and allow targeting of specific subgroups of men and women at risk of poorer access to care. For example, patients presenting without chest pain had a 59\% lower probability of receiving primary percutaneous intervention within the recommended 90 minutes. In addition, patients presenting with several traditional risk factors actually

Table 4: Multivariable logistic regressions: determinants of invasive procedure utilization

\begin{tabular}{|c|c|c|c|}
\hline \multirow[b]{2}{*}{ Factor } & \multicolumn{3}{|c|}{ Procedure; OR $(95 \% \mathrm{Cl})$} \\
\hline & $\begin{array}{c}\text { Cardiac } \\
\text { catheterization }\end{array}$ & $\begin{array}{l}\text { Reperfusion } \\
\text { therapy }\end{array}$ & Nonprimary $\mathrm{PCl}$ \\
\hline \multicolumn{4}{|l|}{ Clinical } \\
\hline $\begin{array}{l}\text { Anxiety, per 1-point increment } \\
\text { on HADS subscale }\end{array}$ & $1.04(0.98-1.10)$ & $1.04(0.96-1.13)$ & $0.96(0.91-1.02)$ \\
\hline $\begin{array}{l}\text { Depression, per 1-point increment } \\
\text { on HADS subscale }\end{array}$ & $0.96(0.91-1.03)$ & $0.97(0.89-1.06)$ & $1.08(1.00-1.15)$ \\
\hline Absence of chest pain & $0.99(0.59-1.64)$ & $0.89(0.42-1.88)$ & $0.66(0.40-1.09)$ \\
\hline Previous event & $0.88(0.55-1.39)$ & $0.70(0.36-1.36)$ & $0.88(0.55-1.42)$ \\
\hline $\begin{array}{l}\text { CVD risk factors, per each added risk } \\
\text { factor }\end{array}$ & $0.97(0.84-1.12)$ & $0.87(0.70-1.07)$ & $1.02(0.98-1.19)$ \\
\hline \multicolumn{4}{|l|}{ Gender-related } \\
\hline Postsecondary education & $0.88(0.55-1.39)$ & $0.96(0.66-1.55)$ & $0.80(0.52-1.24)$ \\
\hline Employed & $1.34(0.84-2.15)$ & $1.63(0.85-3.00)$ & $1.36(0.82-2.26)$ \\
\hline $\begin{array}{l}\text { Perceived social standing within } \\
\text { community (based on PSSS score) }\end{array}$ & $0.95(0.86-1.05)$ & $0.95(0.82-1.10)$ & $1.03(0.93-1.14)$ \\
\hline Responsibility for housework & $0.68(0.46-0.99)$ & $0.69(0.40-1.18)$ & $0.62(0.41-0.95)$ \\
\hline $\begin{array}{l}\text { Low social support (based on ESSI } \\
\text { scale) }\end{array}$ & $1.17(0.74-1.85)$ & $0.60(0.33-1.85)$ & $0.93(0.58-1.52)$ \\
\hline $\begin{array}{l}\text { Femininity, per } 1 \text { - point increment } \\
\text { on Bem scale }\end{array}$ & $1.00(0.80-1.24)$ & $0.93(0.69-1.24)$ & $0.75(0.59-0.95)$ \\
\hline $\begin{array}{l}\text { Masculinity, per 1-point increment } \\
\text { on Bem scale }\end{array}$ & $0.87(0.70-1.08)$ & $1.25(0.93-1.67)$ & $0.97(0.78-1.22)$ \\
\hline \multicolumn{4}{|c|}{$\begin{array}{l}\text { Note: Bem = Bem Sex Role Inventory, }{ }^{11} \mathrm{Cl}=\text { confidence interval, } \mathrm{CVD}=\text { cardiovascular disease, ESSI = ENRICHD (Enhancing } \\
\text { Recovery in Coronary Heart Disease Patients) Social Support Instrument, }{ }^{13} \mathrm{HADS}=\text { Hospital Anxiety and Depression Scale, }{ }^{10} \mathrm{OR}= \\
\text { odds ratio, } \mathrm{PCl}=\text { percutaneous coronary intervention, PSSS = McArthur Perceived Social Standing Scale. }{ }^{12} \\
{ }^{*} \text { The results for each row were adjusted for all other factors in the table, as well as for age and ethnicity; sex was not included } \\
\text { in the model. }\end{array}$} \\
\hline
\end{tabular}


had lower odds of receiving timely fibrinolysis. Presentation with multiple risk factors or atypical presentation may prolong the initial assessment and complicate the treatment algorithm for young patients with premature acute coronary syndrome. This issue would be particularly important for young women, who presented with a heavier burden of traditional risk factors and were less likely to present with chest pain than men.

Among the clinical determinants of procedure delays, anxiety was associated with failure to meet the 10-minute benchmark for ECG in women but not in men. Patients with anxiety who present to the emergency department with noncardiac chest pain tend to be women, ${ }^{19}$ and the prevalence of acute coronary syndrome is lower among young women than among young men. ${ }^{20}$ These findings suggest that triage personnel might initially dismiss a cardiac event among young women with anxiety, which would result in a longer door-to-ECG interval.

A novel finding of our study was the identification of gender-related determinants of access to care. Interestingly, feminine traits of personality (according to the Bem Sex Role Inventory) were associated with a lower likelihood of receiving timely primary percutaneous intervention $(31 \%$ decrease per 1-point increment of the femininity score). In contrast, masculine traits increased the odds of receiving timely fibrinolysis $(62 \%$ increase per 1-point increment of the masculinity score). Men and women who reported higher levels of feminine personality traits, as well as those who reported being the person at home mainly responsible for housework, were also less likely to undergo invasive procedures. Gender-related factors influencing access to care are consistent with the Andersen model of health care utilization. ${ }^{21}$ According to this model, patients' use of health services is a function of their predisposition to receive services, the factors enabling the utilization of such services and their perception of need for care.

Our results showing that women were less likely than men to undergo timely ECG and fibrinolysis as well as invasive procedures are consistent with previous findings for older patients. ${ }^{4,6,22}$ However, we did not observe any differences between men and women with regard to the odds of receiving timely primary percutaneous intervention, in contrast to previous studies showing longer door-to-balloon times among older women than older men. ${ }^{4,6,23}$ This difference may relate to differences in age between the study populations. To our knowledge, this is the first study assessing sex-related differences in and determinants of access to care within a cohort of patients with premature acute coronary syndrome. Age differences between study populations prevent adequate comparison of our results with those of previous studies, especially regarding clinical and gender-related determinants of access to care.

\section{Limitations}

This study had some methodologic limitations. First, the study sample consisted of survivors of acute coronary syndrome, and the participation rate was higher for women than men. These limitations may indicate a selection bias. Second, because of the limited sample size inherent to a study of young adults with acute coronary syndrome, some standard deviations in our multivariable models were wide. Also, data for doorto-ECG and door-to-balloon times were missing for an average of $10 \%$ of patients, and data for annual household income were missing for $18 \%$. However, baseline data were available for all patients for all of the other variables. Patients were excluded from the models that included variables for which they had missing data, which further reduced the sample size for these models. Third, lack of data on the appropriateness of procedures limits the interpretation of results and the implications for clinical practice.

\section{Conclusion}

Overall, our results showed that among younger adults with acute coronary syndrome, women and men had differing access to care. Future studies should assess the appropriateness of care in this population. We also found that low proportions of both men and women met the recommended benchmarks for timeliness of procedures. Identification of clinical and gender-related determinants of access to care further revealed that women with anxiety, as well as men and women with no chest pain, with several traditional risk factors and with a feminine gender identity and role were at increased risk of poor access to care. These groups of patients presenting to the emergency department with cardiac-like symptoms may need targeting for more effective initial management of acute coronary syndrome.

\section{References}

1. Claassen M, Sybrandy KC, Appelman YE, et al. Gender gap in acute coronary heart disease: Myth or reality? World J Cardiol 2012;4:36-47.

2. Lansky AJ, Pietras C, Costa RA, et al. Gender differences in outcomes after primary angioplasty versus primary stenting with and without abciximab for acute myocardial infarction: results of the Controlled Abciximab and Device Investigation to Lower Late Angioplasty Complications (CADILLAC) Trial. Circulation 2005;111:1611-8

3. Valente S, Lazzeri C, Chiostri M, et al. Gender-related difference in ST-elevation myocardial infarction treated with primary angioplasty: a single-centre 6-year registry. Eur J Prev Cardiol 2012; 19:233-40. 
4. Jneid H, Fonarow GC, Cannon CP, et al. Sex differences in medical care and early death after acute myocardial infarction. Circulation 2008;118:2803-10.

5. Tamis-Holland JE, Palazzo A, Stebbins AL, et al. Benefits of direct angioplasty for women and men with acute myocardial infarction: results of the Global Use of Strategies to Open Occluded Arteries in Acute Coronary Syndromes Angioplasty (GUSTO II-B) Angioplasty Substudy. Am Heart J 2004;147:133-9.

6. Collins SD. Acute myocardial infarction in women: Is there a sex disparity between door-to-balloon time and clinical outcomes? Cardiovasc Revasc Med 2012;13:125-7.

7. Enström I, Lidfeldt J, Lindholm LH, et al. Does blood pressure differ between users and non-users of hormone replacement therapy? The Women's Health In the Lund Area (WHILA) Study. Blood Press 2002;11:240-3.

8. Pilote L, Karp I. GENESIS-PRAXY (GENdEr and Sex determInantS of cardiovascular disease: From bench to beyond-Premature Acute Coronary SYndrome). Am Heart J 2012;163:741-6.

9. von Elm E, Altman DG, Egger M, et al. The Strengthening the Reporting of Observational Studies in Epidemiology (STROBE) statement: guidelines for reporting observational studies. Ann Intern Med 2007;147:573-7.

10. Zigmond AS, Snaith RP. The Hospital Anxiety and Depression Scale. Acta Psychiatr Scand 1983;67:361-70.

11. Bem SL. The measurement of psychological androgyny. J Consult Clin Psychol 1974;42:155-62.

12. Adler NE, Epel ES, Castellazzo G, et al. Relationship of subjective and objective social status with psychological and physiological functioning: preliminary data in healthy white women Health Psychol 2000;19:586-92.

13. The ENRICHD Investigators. Enhancing recovery in coronary heart disease patients (ENRICHD): study design and methods. Am Heart J 2000;139:1-9.

14. O'Connor RE, Brady W, Brooks SC, et al. Part 10: acute coronary syndromes: 2010 American Heart Association Guidelines for Cardiopulmonary Resuscitation and Emergency Cardiovascular Care. Circulation 2010;122:S787-817.

15. Bjelland I, Dahl AA, Haug TT, et al. The validity of the Hospital Anxiety and Depression Scale. An updated literature review. $J$ Psychosom Res 2002;52:69-77.

16. Diercks DB, Kirk JD, Lindsell CJ, et al. Door-to-ECG time in patients with chest pain presenting to the ED. Am J Emerg Med 2006;24:1-7.

17. Mohanan PP, Mathew R, Harikrishnan S, et al. Presentation, management, and outcomes of 25748 acute coronary syndrome admissions in Kerala, India: results from the Kerala ACS Registry. Eur Heart J 2013;34:121-9.

18. Stone GW, Grines CL, Browne KF, et al. Comparison of in-hospital outcome in men versus women treated by either thrombolytic therapy or primary coronary angioplasty for acute myocardial infarction. Am J Cardiol 1995;75:987-92.

19. Fagring AJ, Gaston-Johansson F, Kjellgren KI, et al. Unexplained chest pain in relation to psychosocial factors and health-related quality of life in men and women. Eur J Cardiovasc Nurs 2007:6:329-36

20. Lerner DJ, Kannel WB. Patterns of coronary heart disease morbidity and mortality in the sexes: a 26-year follow-up of the Framingham population. Am Heart J 1986;111:383-90.

21. Andersen RM. Revisiting the behavioral model and access to medical care: Does it matter? J Health Soc Behav 1995;36:1-10.

22. Halvorsen S, Eritsland J, Abdelnoor M, et al. Gender differences in management and outcome of acute myocardial infarctions treated in 2006-2007. Cardiology 2009;114:83-8.

23. Kaul P, Armstrong PW, Sookram S, et al. Temporal trends in patient and treatment delay among men and women presenting with STelevation myocardial infarction. Am Heart J 2011;161:91-7.

Affiliations: Division of Clinical Epidemiology (Pelletier, Avgil Tsadok, Pilote), Research Institute of the McGill University Health Centre, Montréal, Que.; Divison of Cardiology (Humphries), University of British Columbia, Vancouver, BC; Department of Cardiology (Shimony), Soroka Univer- sity Medical Center, Ben-Gurion University, Beer-Sheva, Israel; Concordia University (Bacon), Montréal, Que.; Research Centre (Bacon, Lavoie), Hôpital du Sacré-Coeur de Montréal, Montréal, Que.; Université de Québec à Montréal (Lavoie), Montréal, Que.; Departments of Medicine, Cardiac Sciences and Community Health Sciences (Rabi), University of Calgary, Calgary, Alta.; Hospital Research Centre and Department of Social and Preventive Medicine (Karp), Université de Montréal, Montréal, Que.; Division of General Internal Medicine (Pilote), Department of Medicine, McGill University, Montréal, Que.

Contributors: Louise Pilote had full access to all of the data in the study and takes responsibility for the integrity of the data and the accuracy of the data analysis. Roxanne Pelletier, Karin Humphries, Avi Shimony and Louise Pilote were responsible for study concept and design. Karin Humphries, Simon Bacon, Kim Lavoie, Doreen Rabi, Igor Karp and Louise Pilote were responsible for acquisition of data. Roxanne Pelletier, Karin Humphries, Meytal Avgil Tsadok and Louise Pilote were responsible for analysis and interpretation of the data. Roxanne Pelletier and Louise Pilote drafted the manuscript. All authors contributed to revising and editing the manuscript, and all approved the article submitted for publication.

GENESIS-PRAXY investigators: Louise Pilote, Igor Karp, Simon L. Bacon, Jafna L. Cox, Kaberi Dasgupta, Stella S. Daskalopoulou, Mark J. Eisenberg, James Engert, William Ghali, Karin H. Humphries, Nadia Khan, Kim L. Lavoie, Colleen Norris, Doreen Rabi, Derek So, Ken D. Stark, Vicky Tagalakis, Meytal Avgil Tsadok, Roxanne Pelletier, George Thanassoulis, Avi Shimony, Krishan Ramanthan, Jan Kornder, Todd Anderson, Michelle Graham, Madhu Natarajan, Mike Rokoss, Michele Turek, Asim Cheema, Shahar Lavi, Sherryn Roth, Thao Huynh, Viviane Nguyen, Julie Méthot, Michel Doucet, Martine Montigny, Samer Mansour, Claude Lauzon, Tomas Cieza, Michel Nguyen, François Grondin, Peter Fong, Dhananjai Menzies, Nicolas Rodondi. Complete affiliation information, roles within the research team and participating centres are provided in Appendix 1 (available at www.cmaj.ca/lookup/suppl/doi:10.1503/cmaj.131450/-/DC1).

Funding: This study was funded by the Heart and Stroke Foundations of Quebec, Nova Scotia, Alberta, Ontario, British Columbia and Yukon, and Canada and by the Canadian Institutes of Health Research (CIHR). The study sponsors had no role in the design of the study; the collection, analysis or interpretation of data; the writing of the report; or the decision to submit the article for publication. Roxanne Pelletier is supported by a CIHR award. Karin Humphries is funded by the University of British Columbia Heart and Stroke Foundation Professorship in Women's Cardiovascular Health. Simon Bacon and Kim Lavoie are each supported by a CIHR New Investigator award and a Fonds de recherche en santé du Québec (FRSQ) chercheur-boursier award. Doreen Rabi is funded by a Population Health Investigator Award from Alberta Innovates Health Solutions. Igor Karp is a CIHR New Investigator and an FRSQ Junior 1 Scholar. Meytal Avgil Tsadok is funded by a CIHR Award. Louise Pilote holds a James McGill Chair in medicine.

Acknowledgements: The authors would like to acknowledge the contributions of Hassan Behlouli (statistical analyses), Jasmine Poole (study coordination and data management) and all of the study participants. 